\title{
Liver pathology findings in infant with Caroli's syndrome
}

\author{
Blagica Dukova, Boro Ilievski, Snezana Duganovska, \\ Vladimir Chadikovski, Aco Kostovski
}

\begin{abstract}
Introduction: Caroli's syndrome (CS) is a rare congenital disorder characterized by intrahepatic bile duct dilatation and congenital hepatic fibrosis. The clinical features of this condition include signs of portal hypertension, cholangitis and lithiasis. Liver transplantation is the ultimate treatment in most patients with liver failure. Case Report: A three month old infant treated with the diagnosis of biliary atresia, after two liver biopsies presented with distended abdomen, hepatosplenomegaly and signs of portal hypertension. Liver transplantation was preformed after four months. We found ectatic hilar bile ducts and intrahepatic bile duct dilatation. The pathologic finding of congenital hepatic fibrosis and proliferated dilated bile ducts suggested the
\end{abstract}

Blagica Dukova ${ }^{1}$, Boro llievski ${ }^{2}$, Snezana Duganovska ${ }^{3}$, Vladimir Chadikovski ${ }^{4}$, Aco Kostovski ${ }^{5}$

Affiliations: 1 Junior assistant, Pathologist, Institute of pathology, Medical faculty, Skopje, Republic of Macedonia; 2Pathologist, Institute of pathology, Medical faculty, Skopje, Republic of Macedonia; 3Professor, Pathologist, Institute of pathology, Medical faculty, Skopje, Republic of Macedonia; ${ }^{4}$ Pediatric surgeon, University clinic of pediatric surgery, Skopje, Republic of Macedonia; ${ }^{5}$ Professor, Pediatrician, Medical Director of University Children's Hospital, Chief of Department of Pediatric Gastroenterology, University Children's Hospital, Skopje, Republic of Macedonia.

Corresponding Author: Blagica Dukova, Shumadinska 5/18, 1000 Skopje, Republic of Macedonia, Europe; Ph: +38970678209; Fax: + 38923226 948; Email: blagicadr@yahoo.com

Received: 15 December 2011

Accepted: 11 January 2012

Published: 28 February 2012 diagnosis of Caroli's syndrome. Conclusion: Caroli's disease and Caroli's syndrome may represent single disorder distinguished by congenital hepatic fibrosis. Fibrosis itself leads to portal hypertension appearing late in patients with Caroli's disease while it's dynamic and progressive in CS. Elevated white blood cell count is due to recurrent cholangitis, cholestasis and hepatolithiasis. Caroli's disease can be associated with extrahepatic bile duct dilatation, but the exact incidence is not known. CS often is associated with kidney lesions and cardiac disease. Liver transplantation should be preformed early. Symptoms are presented early in life due to congenital and progressive hepatic fibrosis. Caroli's syndrome must be considered in differential diagnosis in neonates with jaundice, ascites and hepatosplenomegaly. The first child with liver transplantation in Republic of Macedonia was diagnosed as Caroli's syndrome.

Keywords: Caroli's syndrome, Caroli's disease, Congenital hepatic fibrosis, Intrahepatic bile duct dilatation

$$
* * * * * * * * *
$$

Dukova B, Ilievski B, Duganovska S, Chadikovski V, Kostovski A. Liver pathology findings in infant with caroli's syndrome. International Journal of Hepatobiliary and Pancreatic Diseases 2012;2:4-8.

Article ID: 100004IJHPDBD2012

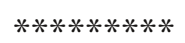

doi:10.5348/ijhpd-2011-4-CR-2 


\section{INTRODUCTION}

Choledochal malformations (CM) are classified into five types according to Todani classification. The fifth type includes Caroli's disease, first described in 1958 by Jacques Caroli as congenital segmental saccular dilatation of the intrahepatic bile ducts. There is a clear relationship of this rare condition with renal anomalies (autosomal recessive polycystic kidney disease and medullary sponge kidney) and intrahepatic fibrosis (combination known as Caroli's syndrome). Recurrent cholangitis due to biliary stasis, jaundice and signs of portal hypertension (e.g. splenomegaly, variceal bleeding, etc) may be found in both Caroli's disease and syndrome. The diagnosis depends on both pathohistology and imaging methods which can show the communication between the sacculi and the bile ducts. This process can be diffuse or limited to one lobe of the liver, more commonly the left lobe. The management varies from symptomatic treatment with antibiotics, surgical drainage procedures to liver transplantation in end stage. We present a case of a three month old boy, who after two liver biopsies underwent liver transplantation and was diagnosed with Caroli's syndrome (CS).

\section{CASE REPORT}

A three month old boy was admitted at Gastrenterohepatology Department of University Children's Hospital because of cholestatic jaundice. He was born at 41 weeks of gestation from controlled pregnancy with a birth weight of 3380 gm and jaundice.

Laboratory results showed elevated conjugated bilirubin - $139 \mu \mathrm{mol} / \mathrm{l}$, total bilirubin - $168 \mu \mathrm{mol} / \mathrm{l}$, elevated serum AST (range from 192 - $278 \mathrm{U} / \mathrm{l}$ ), ALT (range from to 116 - $122 \mathrm{U} / \mathrm{l}$ ), elevated $\gamma \mathrm{GT}$ level (range from $457-584 \mathrm{U} / \mathrm{l}$ ), proteins - $48 \mathrm{gm} / \mathrm{l}$, albumin - 22 $\mathrm{gm} / \mathrm{l}$, normal a1-antytripsine - $1.49 \mathrm{~g} / \mathrm{l}$, normal serum iron - $20 \mu \mathrm{mol} / \mathrm{l}$, a fetoprotein - $6567 \mathrm{IU} / \mathrm{ml}$. All serological markers for viral hepatitis and antibodies for TORCH infections were negative.

Metabolic screening tests for inborn errors of metabolism (aminoacidemia and organic aciduria) were normal.

Tc - 99m iminodiacetic acid scan (HIDA) showed normal uptake by the hepatocytes, after two hours with no activity in the gut. Images taken after three hours and 24 hours showed radioisotope activity in the intestines, consistent with delayed and impaired bile excretion.

MRI cholangiopancreatography revealed hepatomegaly with presence of fibrosis around intrahepatic bile ducts in both liver lobes. Extrahepatic bile ducts were not visible except the upper part of common hepatic duct, finding consistent with biliary atresia.

Ultrasound examination of abdomen showed hapatomegaly and absent gallbladder. The ultrasound of urinary tract, heart and central nervous system excluded any congenital anomalies of these systems.

Liver biopsy showed hyperplastic bile ducts, periportal fibrosis and cholestasis leading to the diagnosis of biliary cirrhosis. After one month the child was admitted to the University Clinic of Pediatric surgery for operative treatment but only open liver biopsy was performed.

Microscopic examination of the liver tissue confirmed the findings from the first biopsy with additional features of necrosis and inflammation.

After one month, at the Emergency Department the child presented with ascites, hepatomegaly $(+5 \mathrm{~cm}$ under costal margins), sepsis and pale stools.

For further examination and treatment the child was hospitalized again at University Clinic of Pediatric surgery where the living donor liver transplantation (LDLT) was made (first procedure for children in our country). The donor was the mother. During the donor operation left liver lobe (II and III segment) was dissected preserving the main vessels from the systemic and portal circulation and the main branches of the biliary tree. Than a hepatectomy was performed and the donor's liver segments were put in place anastomosing donor's hepatic veins with recipient's inferior vena cava. Portal vein was anastomosed termino-terminalis and hepatic artery to proper hepatic artery terminoterminalis. The donor's biliary duct was anastomosed to recipient's small intestine by Roux-en-Y loop.

The liver from the hepatectomy (patient) weighed $650 \mathrm{gm}$ and had nodular, green surface. Hilar bile ducts and the gallbladder were ectatic, gallbladder measuring 11x8 $\mathrm{cm}$. Dissected liver tissue showed diffuse multiple cystic intrahepatal bile ducts with lithiasis (figure $1 \mathrm{~A}$, B).

Histopathologic analysis revealed intensive portal fibrosis, numerous ductal plate remnants, hyperplastic and dilated bile ducts with cholestasis and foci of microabscesses (figures 1-3).

The diagnosis of Caroli's syndrome was made.

Preoperative and postoperative laboratory results are shown in table 1.

The child had two attacks of acute rejection but resolved with immunosuppressants with Prograf (tacrolimus), Cellcept (mycophenolate), mofetil, Soludecortin, Simulect (rapamycine); treated at University Clinic of anesthesiology, reanimation and intensive care. At nine months of age the child died and postmortem examination revealed biliary complications, multiple hepatal graft necrotic areas and sepsis.

\section{DISCUSSION}

Caroli's disease is described in two forms; the so called "pure form" characterized by saccular, communicating intrahepatic bile duct dilatation and the second form which has intrahepatic bile duct ectasia and proliferation associated with hepatic fibrosis known as Caroli's syndrome. It is unclear whether these two types 

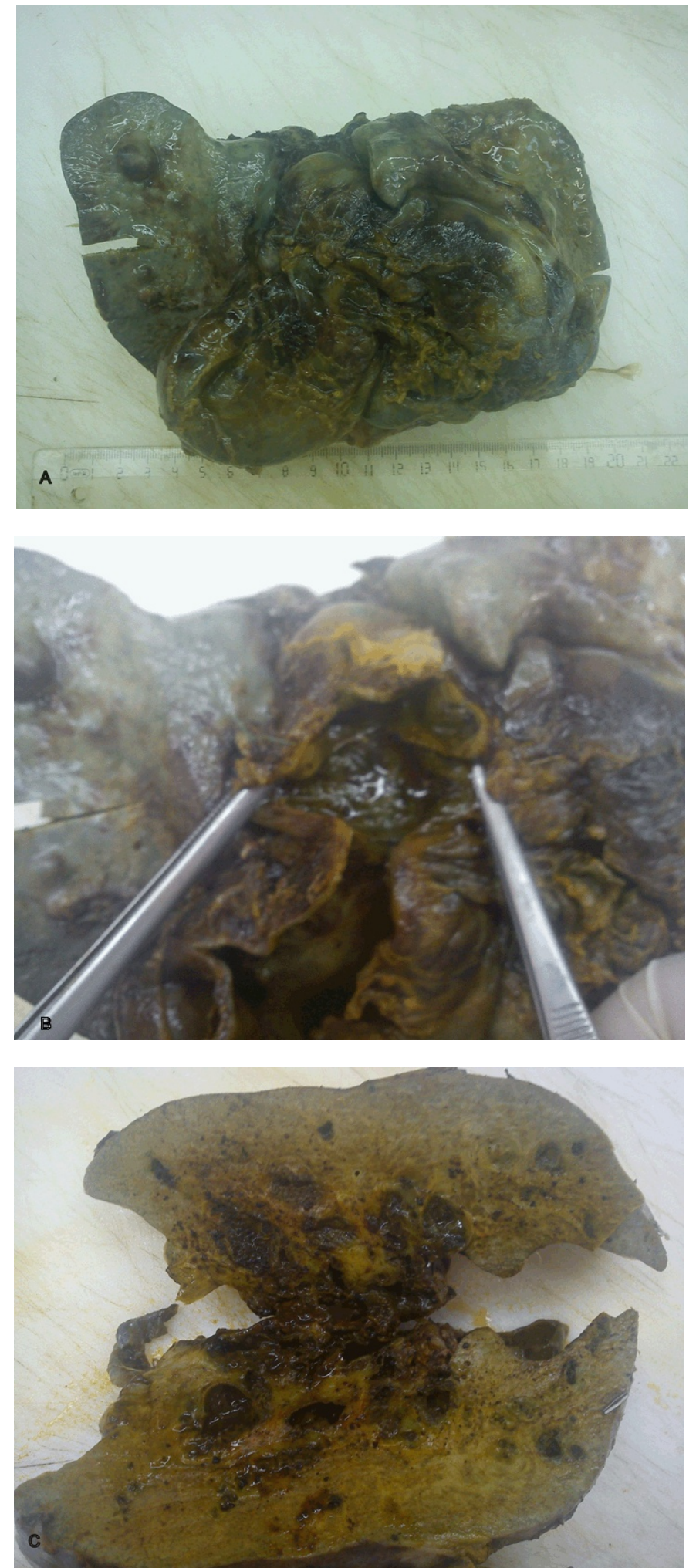

Figure 1: A) Gross view of liver hilar side, B) ectatic gallbladder and hilar bile ducts, C) cystic intrahepatic bile ducts.

represent distinct entities or a single disorder distinguished by hepatic fibrosis. Many authors believe that the two conditions are different stages of the same disease $[1,2,3]$. Clinical progression and presentation of
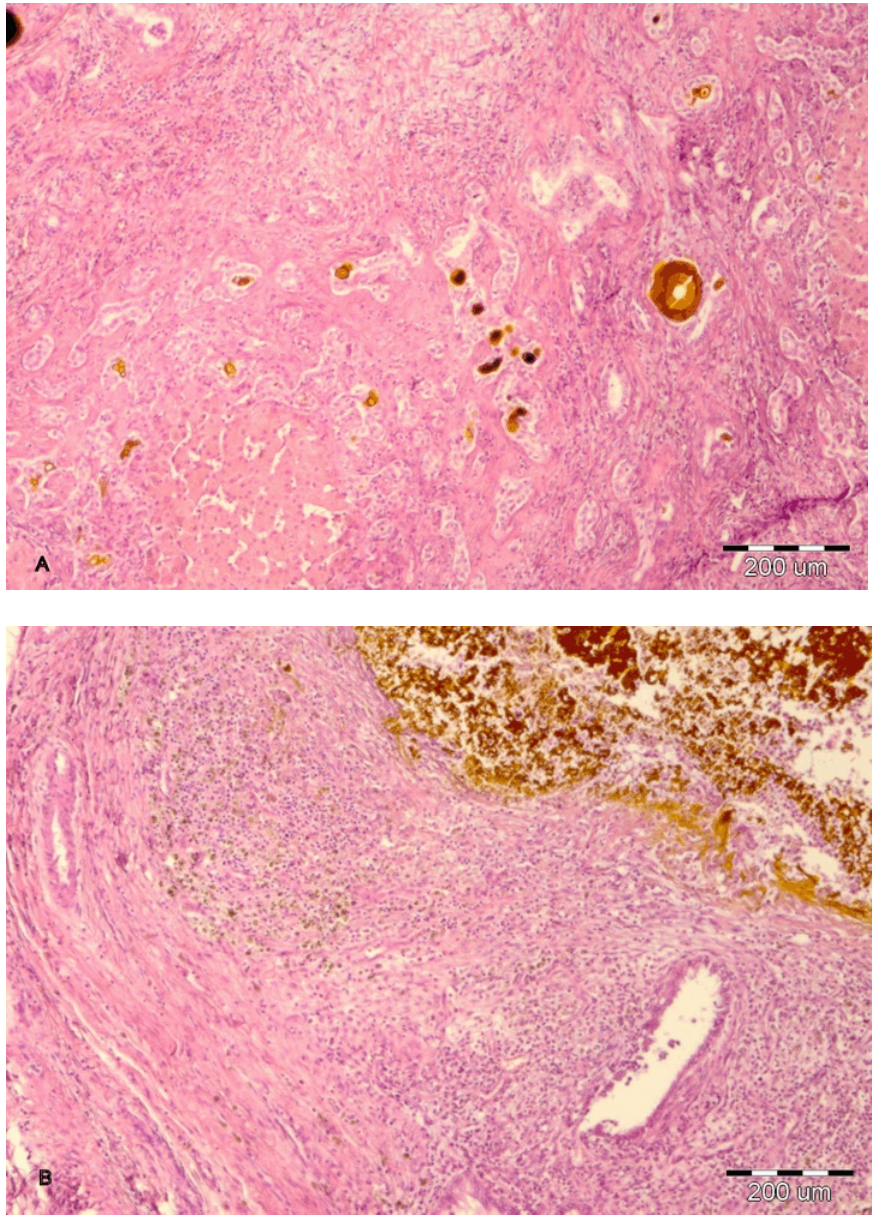

Figure 2: A) Portal fibrosis, dilated bile ducts with cholestasis (HE, x40), B) severe inflammatory response around cystic bile duct (HE, X4O).

CS is highly variable and symptoms may appear early or late during life. Congenital hepatic fibrosis leads to portal hypertension and development of esophageal varices, hematemesis or melena. In patients with Caroli's disease these symptoms appear late suggesting congenital hepatic fibrosis in Caroli's syndrome is dynamic and progressive. Recurrent cholangitis is explained by cholestasis and hepatolithiasis, resulting in elevated white blood cell count or erythrocyte sedimentation [3].

Many theories are explaining the pathogenesis of CS, but the most acceptable for some is the one related to ductal plate malformation at different levels of the intrahepatic biliary tree [3]. Recent studies of Erika Makin et al. [4] showed relationship between histological appearance of biliary epithelium in excised choledochal malformation and increased choledochal pressure.

The differential diagnosis includes polycystic kidney disease, obstructive bile duct dilatation, primary sclerosing cholangitis, biliary papilomatosis and choledochal cyst. Pathohistologic findings of dilated and hyperplastic bile ducts accompanied with congenital hepatal fibrosis confirmed the diagnosis of Caroli's syndrome in our case. 

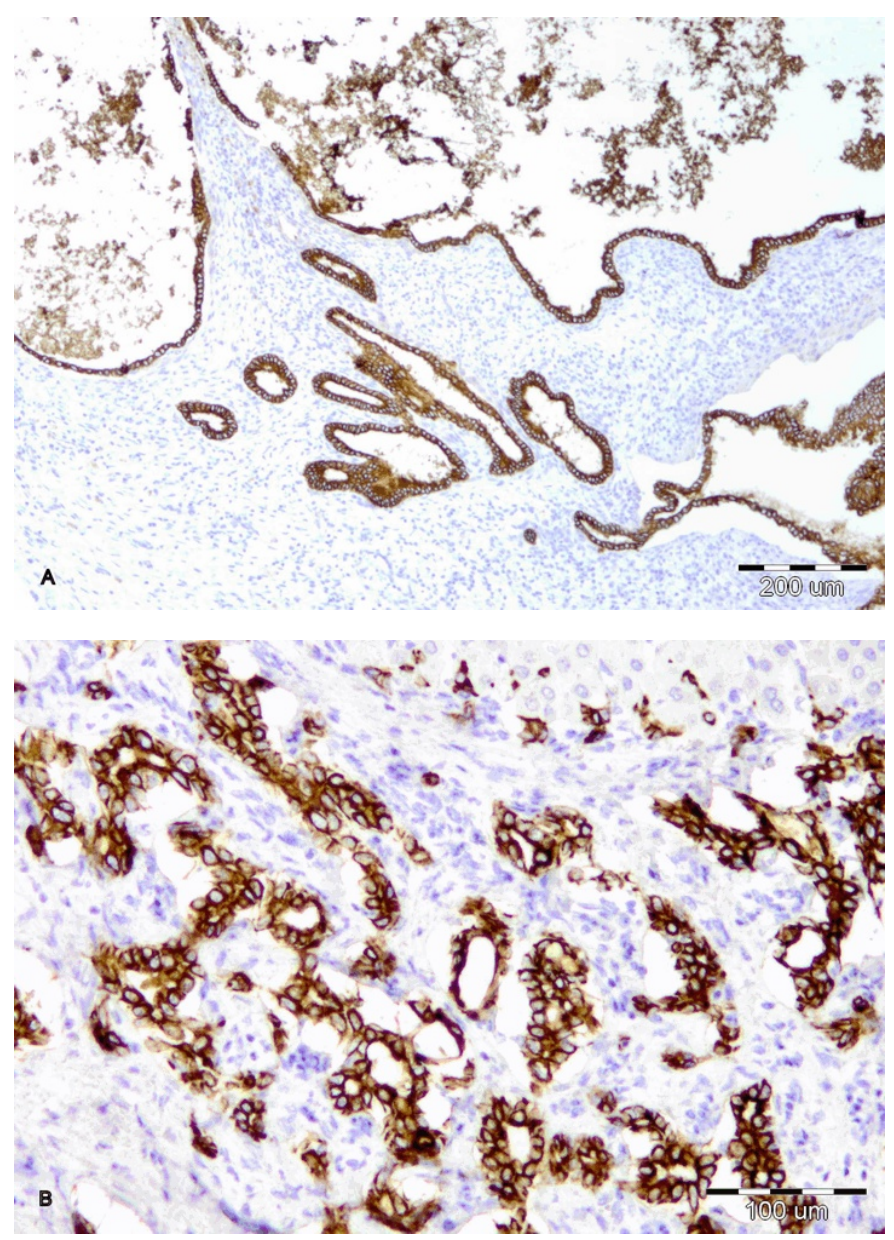

Figure 3: A) Cuboidal biliary epithelium lining ectatic ducts (CK19, X40), B) numerous ductal plate remnants (CK19, x100).
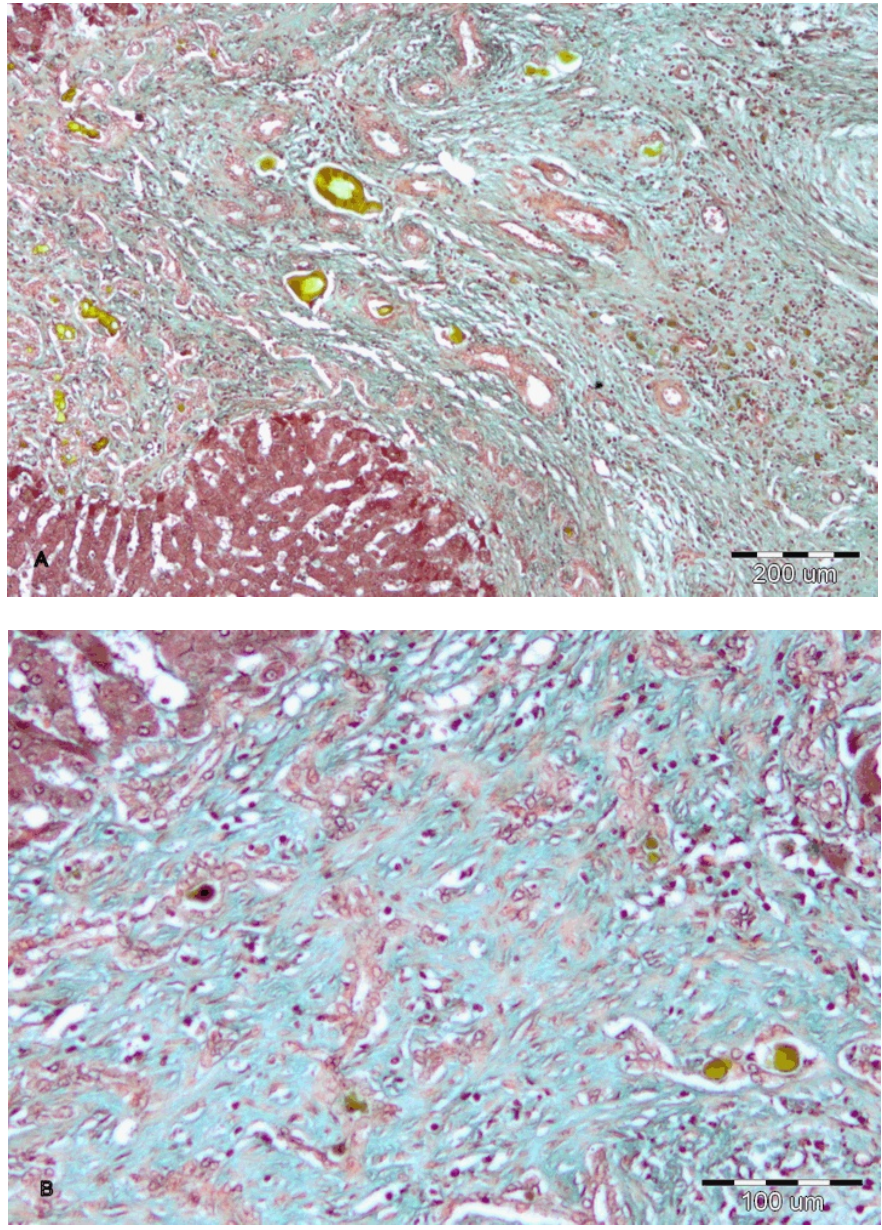

Figure 4: Congenital hepatic fibrosis. (Massoris Trichrome, A$\mathrm{x} 40, \mathrm{~B}-\mathrm{x} 100$ )

Table 1: Laboratory results (pre and postoperative).

\begin{tabular}{|c|c|c|c|c|}
\hline & Preoperative & Postoperative & Postoperative (One month) & Normal values \\
\hline Hct (\%) & 39.1 & 37.4 & 34 & $36-46(F), 41-53(\mu)$ \\
\hline $\mathrm{WBC}\left(\mathrm{x} 10^{9} / \mathrm{L}\right)$ & 23.4 & 12.5 & 14.2 & \\
\hline $\operatorname{PLT}\left(\mathrm{x} 10^{9} / \mathrm{L}\right)$ & 234 & 100 & 104 & $4-11,1.5-4.5$ \\
\hline Glucose (mmol) & 4.9 & 6.27 & 5.47 & $3.49-5.01$ \\
\hline $\mathrm{CRP}(\mathrm{mg} / \mathrm{L})$ & 75.2 & 137.8 & 31 & $0.00-5.00$ \\
\hline $\operatorname{AST}(\mathrm{U} / \mathrm{L})$ & 84 & 351.5 & 71.6 & $0.0-40.0$ \\
\hline $\operatorname{ALT}(\mathrm{U} / \mathrm{L})$ & 40 & 275.1 & 141.1 & $0.0-41.0$ \\
\hline GGT (U/L) & 456 & $337 \cdot 7$ & 420.6 & $6.0-71.0$ \\
\hline $\operatorname{ALP}(\mathrm{U} / \mathrm{L})$ & 650 & 247.6 & 222.2 & $35 \cdot 0-129.0$ \\
\hline Urea $(\mathrm{mmol} / \mathrm{L})$ & $5 \cdot 3$ & 3.82 & $5 \cdot 5^{2}$ & $0.00-8.30$ \\
\hline Creatinine (umol/L) & 12 & $<18$ & $<18$ & $50-106$ \\
\hline Bilirubin total (umol/L) & 111 & 14.7 & 8.9 & $0.0-17.1$ \\
\hline Bilirubin direct (umol/L) & 90 & & 5.21 & $0.0-3.4$ \\
\hline Total protein $(\mathrm{g} / \mathrm{L})$ & 72 & 47 & 50 & $66-87$ \\
\hline Albumin $(\mathrm{g} / \mathrm{L})$ & 33 & 30 & 31 & $34-48$ \\
\hline
\end{tabular}


Caroli's disease can be associated with extrahepatic bile duct dilatation, but the exact incidence is not known. Literature review of 37 cases found extrahepatic dilatation in 21\% of patients [5]. Angela Levy et al. [6] analyzed series of 17 patients (five with Caroli's syndrome) and found higher ratio 53\% of patients with extrahepatic duct dilatation. Our patient also revealed extrahepatic and intrahepatic bile duct ectasia.

CS often is associated with autosomal recessive polycystic kidney disease, renal failure or cardiac disease $[7,8]$. These features were not exhibited in the case.

Liver transplantation seems to be the ultimate curative treatment in these patients and should be preformed early $[9,10]$. The child in this reported case was seven months old when liver transplantation was made. Precautions that should be taken in following these patients include adequate pre-transplant preparation and decreased risk of post-transplant infections.

According to European Liver Transplant Registry 2010, the primary indication for liver transplantation in children under two years are cholestatic diseases in $75 \%$ and the one to three years survival is $83-80 \%$.

\section{CONCLUSION}

Our case discussed here is a boy with features of severe portal hypertension, cholestasis and cholangitis, who after liver transplantation and histopathological analysis was diagnosed with Caroli's syndrome. It is the first reported case of CS manifested in neonatal period in Republic of Macedonia. At the same time it was the first procedure for liver transplantation in a child made in our country. Although rare, CS should be considered in the differential diagnosis in neonates with jaundice, hepatosplenomegaly, intra- and extra-hepatic biliary dilatation and histologic findings of congenital hepatic fibrosis.

$* * * * * * * * *$

\section{Author's Contribution}

Blagica Dukova - Conception and design, Acquisition of data, Analysis and interpretation of data, Drafting the article, Final approval of the version to be published Boro Ilievski - Acquisition of data, Critical revision of the article, Final approval of the version to be published Snezana Duganovska - Acquisition of data, Critical revision of the article, Final approval of the version to be published

Vladimir Chadikovski - Acquisition of data, Analysis and interpretation of data, Critical revision of the article, Final approval of the version to be published

Aco Kostovski - Acquisition of data, Analysis and interpretation of data, Critical revision of the article, Final approval of the version to be published

\section{Guarantor}

The corresponding author is the guarantor of submission.

\section{Conflict of Interest}

The authors declare no conflict of interest.

\section{Copyright}

(C) Blagica Dukova et al. 2012; This article is distributed under the terms of Creative Commons attribution 3.0 License which permits unrestricted use, distribution and reproduction in any means provided the original authors and original publisher are properly credited. (Please see www.ijhpd.com/copyright-policy.php for more information.)

\section{REFERENCES}

1. Bavikar R, Kulkarni R. Caroli's syndrome:a case report. Curr Pediatr Res 2011;15(1):59-60.

2. Rao YK, Midha T. Caroli's syndrome with ureterovesical calculi in a yang child. Indian $\mathrm{J}$ Pediatr 2010;77(6):701-2.

3. Yonem O, Bayraktar Y. Clinical characteristics of Caroli's syndrome. World J Gastroenterol 2007;13(13):1934-7.

4. Makin E, Davenport M . Understanding choledochal malformation. Arch Dis Child [doi:10.1136/adc.2010.195974] 2011. Available at http://adc.bmj.com/content/early/2011/o3/27/adc. 2010.195974.full.Accessed November 16, 2011.

5. Todani T, Watanabe $\mathrm{Y}$, Narusue $\mathrm{M}$, Tabuchi K, Okajima K. Congenital bile duct cysts: classification, operative procedures, and review of thirty-seven cases including cancer arising from choledochal cyst. Am J Surg 1977;134:263-9.

6. Levy AD, Rohrmann CA Jr, Murakata LA, Lonergan GJ. Caroli's disease: radiologic spectrum with pathologic correlation. AJR 2002;179:1053-7.

7. Kim JT, Hur YJ, Park JM, Kim MJ, Park YN, Lee JS. Caroli's syndrome with autosomal recessive polycystic kidney disease in a two month old infant. Yonsei Med J 2006;47(1):131-4.

8. Keane F, Hdzic N, Wilkinson ML, Qureshi S, Reid C, Baker AJ et al. Neonatal presentation of Caroli's disease. Arch Dis Child Fetal Neonatal ed 1997;77:F145-6.

9. Wang ZX, Yan LN, Li B, Zeng Y, Wen TF, Wang WT. Orthotopic liver transplantation for patients with Caroli's disease. Hepatobiliary Pancreat Dis Int 2008;7:97-100.

10. Dong Q, Jiang BX, Jiang Z, Zhang H, Zhao N, Jiang $\mathrm{XM}$ et al. Management of congenital choledochal cyst complicated by biliary anomalies and aberrant bile duct. World J Pediatr 2006;2:133-8. 